Errno::ENOENT: No such file or directory @ rb_sysopen - main.scss

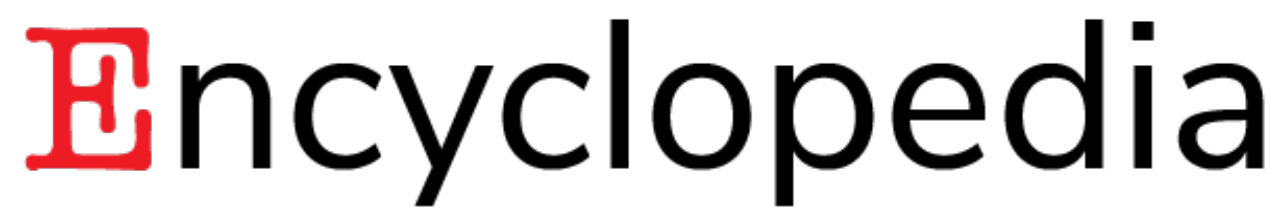

\title{
Stress Corrosion Cracks in Pipeline Steels
}

Created by: Mohammad Ali Mohtadi Bonab

Version received: 29 May 2019

check for updates

The demand for pipeline steels has increased in the last several decades since they were able to provide an immune and economical way to carry oil and natural gas over long distances. There are two important damage modes in pipeline steels including stress corrosion cracking (SCC) and hydrogen induced cracking (HIC). The SCC cracks are those cracks which are induced due to the combined effects of a corrosive environment and sustained tensile stress. The present review article is an attempt to highlight important factors affecting the SCC in pipeline steels. Based on a literature survey, it is concluded that many factors, such as microstructure of steel, residual stresses, chemical Composition of steel, applied load, alternating current $(\mathrm{AC})$ current and texture, and grain boundary character affect the SCC crack initiation and propagation in pipeline steels. It is also found that crystallographic texture plays a key role in crack propagation. Grain boundaries associated with $\{111\} / /$ rolling plane, $\{110\} / /$ rolling plane, coincidence site lattice boundaries and low angle grain boundaries are recognized as crack resistant paths while grains with high angle grain boundaries provide easy path for the SCC intergranular crack propagation. Finally, the SCC resistance in pipeline steels is improved by modifying the microstructure of steel or controlling the texture and grain boundary character.

Table of Content [Hide]

\section{Introduction}

The demand for energy has increased in recent decades which forced the industry to develop high resistance pipeline steels $[1,2,3]$. Such steels show better mechanical properties and a higher corrosion resistance compared with normal carbon steels. However, these steels still suffer from two important failure modes including hydrogen induced cracking (HIC) and stress corrosion cracking (SCC) $[4,5,6]$. There are numerous studies in the literature focused on these failure modes. The SCC has been recognized as one of the main important failure modes in humid environments and causes a huge amount of economical loss and environmental disasters all around the world. The SCC susceptibility in pipeline steels depends on various factors such as $\mathrm{t}^{[1]}$ he microstructure of steel, distribution of inclusions and precipitates inside the steel, texture and micro-texture of steel, chemical composition of steel, $\mathrm{pH}$ of the oil and gas which is transported, the $\mathrm{pH}$ of soil and environment where the pipeline steel is buried, and many other factors. Importance of the SCC in pipeline failure motivated us to write this review paper. This paper concentrates on different factors affecting the SCC crack nucleation and propagation in pipeline steel and looks for new ways to increase the resistance of pipeline steels to the SCC.

The microstructure of API X60 and X70 pipeline steels has been mainly composed of polygonal and acicular ferrite. Moreover, there are some particles of martensite in the microstructure of both steels [7]. The microstructure of X65 steel includes mostly ferrite and some pearlite [10]. When the strength of pipeline steel increases, the microstructure becomes different from other types of steels. For example, the microstructure of $X 80$ and $X 100$ pipeline steels is mainly formed from ferrite and bainite $[11,12]$. There are also some martensite particles in the microstructure of both X80 and X100 steels. The microstructure of L360NS pipeline steel has been composed of white blocky polygonal ferrite, gray irregular blocky quasipolygonal ferrite and black blocky pearlite colony [10].

\section{Explanation of SCC and HIC}

The HIC and the SCC are categorized as two types of corrosion that occur in pipeline steels. Since they 
have a close correlation, it is necessary to define both. In order to have an accurate definition of the HIC and the SCC, it would be better to explain the corrosion concept. Corrosion is the material degradation due to environmental effects. During the corrosion process, electrons are released due to the metal dissolution at anodic site [13]. Such electrons transfer to the cathode, where oxygenated water is reduced to hydrogel ions. The following overall reactions occur during the metal corrosion.

Anodic dissolution:

$$
\mathrm{Fe} \rightarrow \mathrm{Fe}^{+2}+2 \mathrm{e}^{-}
$$

(1)

Figure 1 shows how a rust begins with the oxidation of iron to ferrous ions. The rust formation is a very complicated process, which begins with the oxidation of iron.

$$
\text { Oxidation at anode: } 2 \mathrm{H}_{2} \mathrm{O}(\mathrm{l}) \rightarrow \mathrm{O}_{2}(\mathrm{~g})+4 \mathrm{H}^{+}(\mathrm{aq})+4 \mathrm{e}^{-}
$$

Oxygen reduction in neutral or alkalis media: $\mathrm{O}_{2}+2 \mathrm{H}_{2} \mathrm{O}+4 \mathrm{e}^{-} \rightarrow 4 \mathrm{OH}^{-}$

Oxygen reduction in acidic media: $\mathrm{O}_{2}+4 \mathrm{H}+4 \mathrm{e}^{-} \rightarrow 2 \mathrm{H}_{2} \mathrm{O}$

Overall corrosion reaction: $\mathrm{Fe}+2 \mathrm{H}^{+} \rightarrow \mathrm{Fe}^{+2}+\mathrm{H}^{2}$

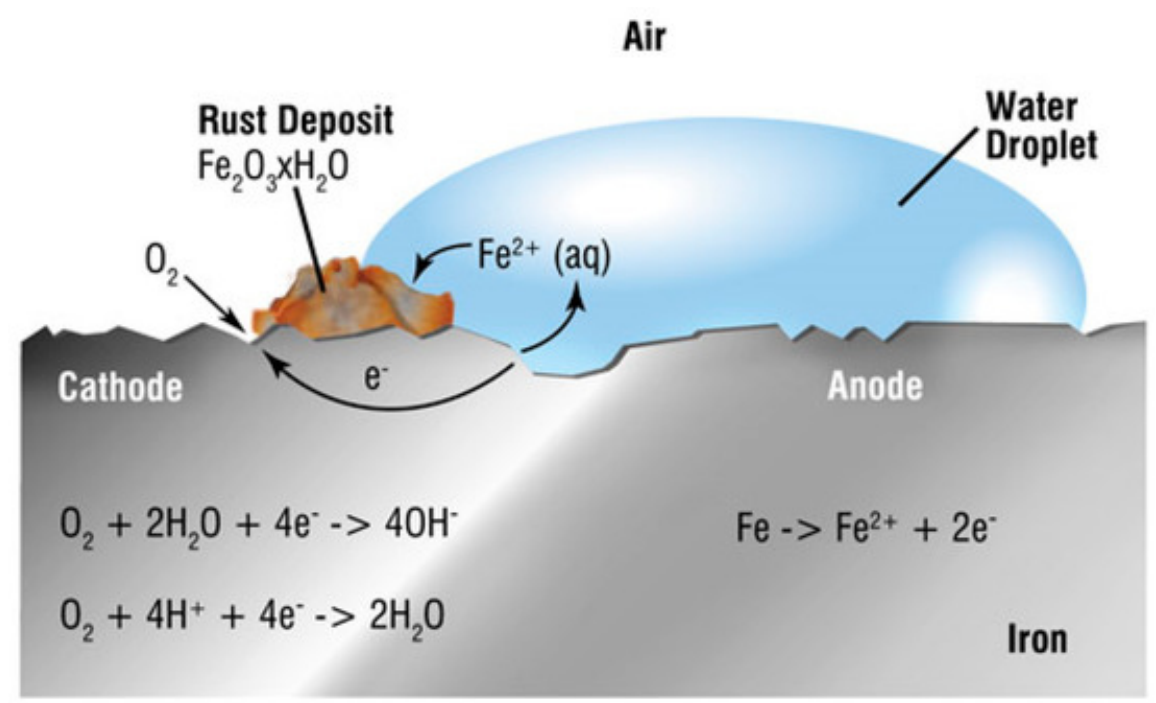

Figure 1. Formation of rust by the oxidation of iron to ferrous ions [13]. Reproduced with permission from [13], Noria Corporation and Machinery Lubrication, 2018.

The SCC cracks are cracks that are induced due to the combined effect of the corrosive environment and sustained tensile stress. The tensile stress can be directly applied inside the pipeline or can be in the form of residual tensile stress. Therefore, three parameters including, a susceptible material (pipeline steel), a specific chemical species (environment), and tensile stress are required for crack nucleation and propagation. Therefore, the SCC is a type of environmentally assisted cracking (EAC), which is of great interest to the oil and gas pipeline manufactures. Recently, thousands of colonies of the SCC cracks have been observed in pipeline steels. Such cracks usually become dormant at depth of $1 \mathrm{~mm}$. However, sometimes these cracks result in failure of pipeline by crack propagation [14]. Figure 2 shows effective factors influencing SCC crack initiation in pipeline steels. 


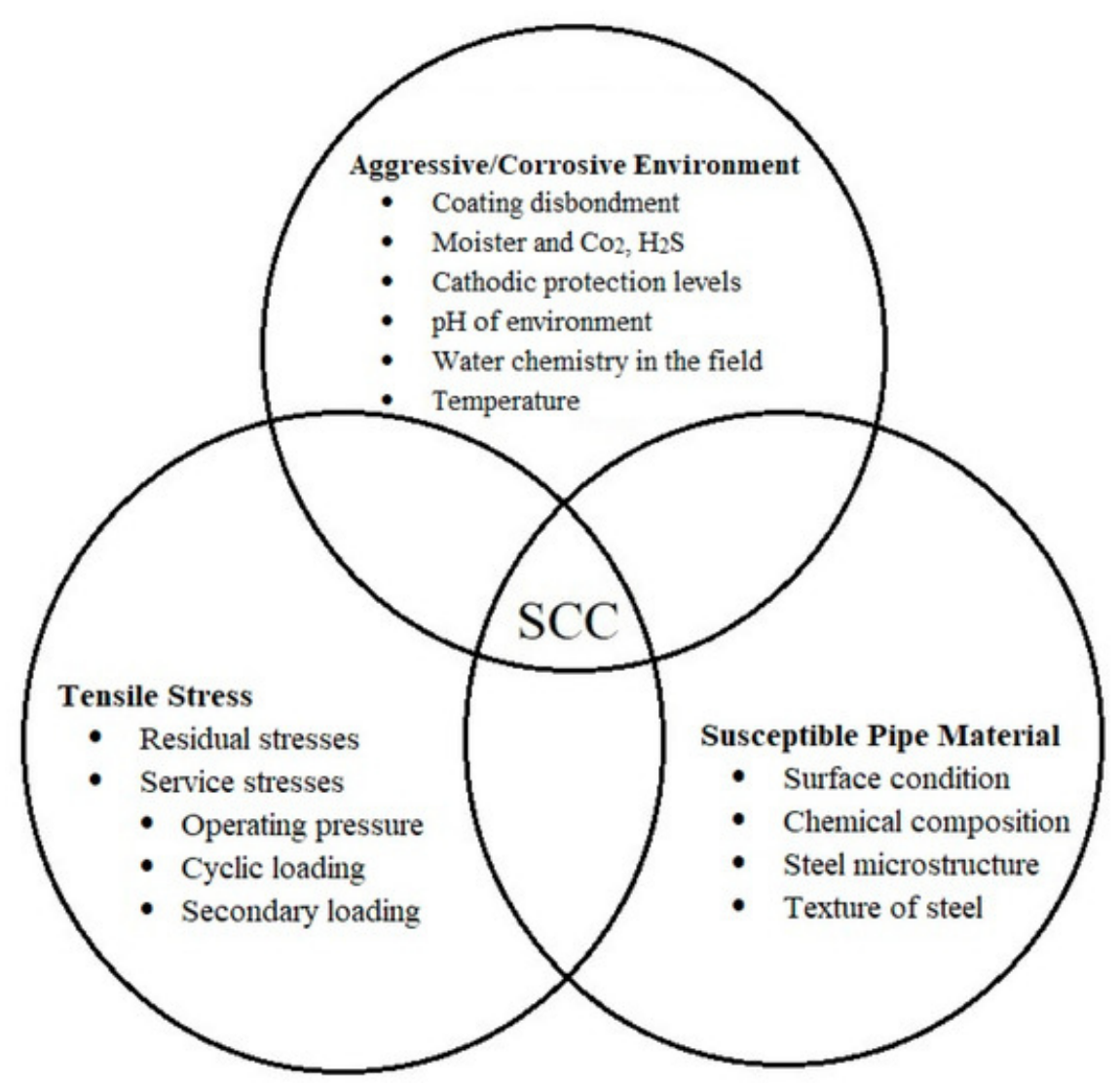

Figure 2. Effective factors for the stress corrosion cracking (SCC) crack initiation in pipeline steels.

Several factors such as microstructure, chemical composition, residual stress, texture of steel, water chemistry in the field, applied stress, $\mathrm{pH}$ of environment and AC current density may affect the SCC crack nucleation and propagation in pipeline steels, see Figure $2[15,16,17,18,19,20]$. Two types of corrosion happen in pipeline steels [21]. The first one is the sweet corrosion, which happens due to the presence of $\mathrm{CO}_{2}$. The sweet corrosion [21] in carbon steels is formed in an acidic solution by mixing the $\mathrm{CO}_{2}$ and water. The corrodant material is $\mathrm{H}^{+}$which is derived from $\mathrm{H}_{2} \mathrm{CO}_{3}$. The $\mathrm{CO}_{2}$ gas is entered during some processes such as injection of $\mathrm{CO}_{2}$ gas into the steel during the recovery operation. The sweet corrosion starts with the reaction of $\mathrm{Fe}$ and $\mathrm{CO}_{2}$. This reaction can be written as follows:

$$
\mathrm{Fe}+\mathrm{CO}_{2} \rightarrow \mathrm{FeCO}_{2}
$$

The reaction between the adsorbed surface complex with water produces $\mathrm{Fe}^{2+}(\mathrm{aq})$ and $\mathrm{H}_{2} \mathrm{CO}^{3}$. This reaction provides the cathodic reactant $\mathrm{H}^{+}$during dissociation. The cathodic reaction can be written as follows:

$$
\begin{gathered}
2 \mathrm{H}^{+}(\mathrm{aq})+2 \mathrm{e}^{-} \rightarrow \mathrm{H}_{2} \\
(7) \\
2 \mathrm{H}_{2} \mathrm{CO}_{3}+2 \mathrm{e}^{-} \rightarrow \mathrm{H}_{2}+2 \mathrm{HCO}_{3}^{-}
\end{gathered}
$$

The dissociation of $\mathrm{H}_{2} \mathrm{CO}_{3}$ in solution creates hydrogen ion for cathodic reaction.

$$
\mathrm{H}_{2} \mathrm{CO}_{3}+\mathrm{e}^{-} \rightarrow \mathrm{H}^{+}+\mathrm{HCO}_{3}^{-}
$$

Several studies have been focused on sweet corrosion [21], however, the mechanism of a cathodic reaction has not been fully understood. It was shown that when a $\mathrm{pH}$ value is lower than 4 , the hydrogen reduction is the dominant mode for the corrosion. However, when the $\mathrm{pH}$ value varies between 4 and 7 , the adsorbed $\mathrm{H}_{2} \mathrm{CO}_{3}$ reduction is considerable. This type of corrosion is called sweet corrosion since it occurs with the absence of hydrogen sulphide or high levels of hydrogen sulphide. Carbon dioxide or carbonic acid are the main causes of sweet corrosion.

The second type and more common type of corrosion occurs owing to the presence of hydrogen sulphide $\left(\mathrm{H}_{2} \mathrm{~S}\right)$. Hydrogen sulphide which is present in oil and natural gas is decomposed to $\mathrm{H}^{+}$and $\mathrm{HS}^{-}$. HS ion acts as a hydrogen recombination poison and avoid hydrogen molecule formation [7]. The following reactions occur:

$$
\mathrm{H}_{2} \mathrm{~S} \rightarrow \mathrm{HS}^{-}+\mathrm{H}^{+}
$$


Hydrogen atoms in the forms of protons get electrons from the iron and converted to the hydrogen atoms based on the following equations:

$$
\begin{aligned}
& \mathrm{H}^{+}+\mathrm{e}^{-} \rightarrow \mathrm{H}_{\text {ads }}(12) \\
& \mathrm{H}_{\mathrm{ads}}+\mathrm{H}_{\mathrm{ads}} \rightarrow \mathrm{H}_{2}
\end{aligned}
$$

It is worth mentioning that the hydrogen atoms are accumulated at microstructural defects such as empty spaces between inclusions and precipitates and metal matrix. The hydrogen atoms are combined at these regions and create a high amount of pressure. When this pressure reaches a critical value, the cracks initiate. Such cracks are known as hydrogen-induced cracks. The cavities or empty spaces are formed between inclusions and the metal matrix due to the difference between their thermal expansion coefficients. These cavities are formed during solidification of slabs or hot rolling process and can capture hydrogen atoms due to their small sizes. When the hydrogen atoms are accumulated in these areas, they combine to make hydrogen molecules, which make a high amount of pressure. The following equation shows the Gibbs free energy for hydrogen atoms combination.

$$
\Delta \mathrm{rGH}=\Delta \mathrm{rG \Theta H}+\mathrm{RT} \ln \mathrm{pH} 2 / \mathrm{p \Theta C} 2 \mathrm{H}(14)
$$

In the above equation, $\Delta \mathrm{rG \Theta H}$ is the reaction standard Gibbs free energy, $\mathrm{T}$ and $\mathrm{R}$ are the reaction temperature and gas constant and $\mathrm{CH}$ and $\mathrm{p} \Theta$ re the concentration of hydrogen atoms near the inclusion and standard atmospheric pressure. When the concentration of $\mathrm{H}$ atoms around the inclusions reach a certain value, the reaction will occur and hydrogen molecules are formed. Based on the above equation, the increase of $\mathrm{C}_{\mathrm{H}}$ at the reaction interface will decrease the reaction Gibbs free energy and further leads to the production of $\mathrm{H}_{2}$ molecules. Hydrogen molecule formation creates a high amount of pressure and this results in hydrogen-induced cracks.

References:[2][3][4][5][6][7][8][9][10][11][12][13][14][15][16][17][18][19][20][21]

\section{References}

1. Z.Y. Liu; X.G. Li; C.W. Du; L. Lu; Y.R. Zhang; Y.F. Cheng; Effect of inclusions on initiation of stress corrosion cracks in X70 pipeline steel in an acidic soil environment. Corrosion Science 2009, 51, 895900, 10.1016/j.corsci.2009.01.007.

2. Xian-Bo Shi; Wei Yan; Wei Wang; Lian-Yu Zhao; Yi-Yin Shan; Ke Yang; HIC and SSC Behavior of HighStrength Pipeline Steels. Acta Metallurgica Sinica (English Letters) 2015, 28, 799-808, 10.1007/s40195015-0257-1.

3. T. Hara; H. Asahi; H. Ogawa; Conditions of Hydrogen-Induced Corrosion Occurrence of X65 Grade Line Pipe Steels in Sour Environments. CORROSION 2004, 60, 1113-1121, 10.5006/1.3299225.

4. Xian-Bo Shi; Wei Yan; Wei Wang; Lian-Yu Zhao; Yi-Yin Shan; Ke Yang; Effect of Microstructure on Hydrogen Induced Cracking Behavior of a High Deformability Pipeline Steel. Journal of Iron and Steel Research International 2015, 22, 937-942, 10.1016/s1006-706x(15)30093-5.

5. Wan Keun Kim; Seong Ung Koh; Boo Young Yang; Kyoo Young Kim; Effect of environmental and metallurgical factors on hydrogen induced cracking of HSLA steels. Corrosion Science 2008, 50, 33363342, 10.1016/j.corsci.2008.09.030.

6. Joseph Maciejewski; The Effects of Sulfide Inclusions on Mechanical Properties and Failures of Steel Components. Journal of Failure Analysis and Prevention 2015, 15, 169-178, 10.1007/s11668-015-9940-9.

7. M.A. Mohtadi-Bonab; J.A. Szpunar; Seyed Salman Razavi-Tousi; A comparative study of hydrogen induced cracking behavior in API $5 \mathrm{~L}$ X60 and X70 pipeline steels. Engineering Failure Analysis 2013, 33 , 163-175, 10.1016/j.engfailanal.2013.04.028.

8. M. A. Mohtadi-Bonab; M. Eskandari; R. Karimdadashi; J. A. Szpunar; Effect of different microstructural parameters on hydrogen induced cracking in an API X70 pipeline steel. Metals and Materials International 2017, 23, 726-735, 10.1007/s12540-017-6691-z.

9. Zhou Fan; Xiaogang Hu; Jianyi Liu; Hongchuan Li; Jinwen Fu; Stress corrosion cracking of L360NS pipeline steel in sulfur environment. Petroleum 2017, 3, 377-383, 10.1016/j. petlm.2017.03.006.

10. M. A. Mohtadi-Bonab; M. Eskandari; H. Ghaednia; S. Das; Effect of Microstructural Parameters on Fatigue 
Crack Propagation in an API X65 Pipeline Steel. Journal of Materials Engineering and Performance 2016, 25, 4933-4940, 10.1007/s11665-016-2335-6.

11. M.A. Arafin; J.A. Szpunar; Effect of bainitic microstructure on the susceptibility of pipeline steels to hydrogen induced cracking. Materials Science and Engineering: A 2011, 528, 4927-4940, 10.1016/j.msea.2011.03.036.

12. M.A. Arafin; J.A. Szpunar; A new understanding of intergranular stress corrosion cracking resistance of pipeline steel through grain boundary character and crystallographic texture studies. Corrosion Science 2009, 51, 119-128, 10.1016/j.corsci.2008.10.006.

13. J. Wright; Inhibiting rust and corrosion to prevent machine failures. In Proceedings of the Machinary Lubrication Conference and Exhibition 2018, 1, 1-10, No DOI.

14. National Energy Board.; Stress Corrosion Cracking on Canadian Oil and Gas Pipelines. National Energy Board. 1996, 1, 1-10, No DOI.

15. O.F. Aly; M.M. Neto; Stress Corrosion Cracking, Developments in Corrosion Protection. IntechOpen Limited: London, UK 2014, 1, 1-10, No DOI.

16. J. M. Sutcliffe; R. R. Fessler; W. K. Boyd; R. N. Parkins; Stress Corrosion Cracking of Carbon Steel in Carbonate Solutions. CORROSION 1972, 28, 313-320, 10.5006/0010-9312-28.8.313.

17. John A. Beavers; Brent A. Harle; Mechanisms of High-pH and Near-Neutral-pH SCC of Underground Pipelines. Journal of Offshore Mechanics and Arctic Engineering 2001, 123, 147-151, $10.1115 / 1.1376716$.

18. E. A. Charles; R. N. Parkins; Generation of Stress Corrosion Cracking Environments at Pipeline Surfaces. CORROSION 1995, 51, 518-527, 10.5006/1.3294372.

19. B. Y. Fang; Andrej Atrens; J. Q. Wang; E. H. Han; Z. Y. Zhu; W. Ke; Review of stress corrosion cracking of pipeline steels in "low" and "high" pH solutions. Journal of Materials Science 2003, 38, 127-132, 10.1023/a:1021126202539.

20. M. A. Mohtadi-Bonab; H. Ghesmati-Kucheki; Important Factors on the Failure of Pipeline Steels with Focus on Hydrogen Induced Cracks and Improvement of Their Resistance: Review Paper. Metals and Materials International 2019, 1, 1-26, 10.1007/s12540-019-00266-7.

21. M.G. Kadhim; M. Albdiry; A critical review on corrosion and its prevention in the oilfield equipment. Journal of Petroleum Research \& Studies 2017, 14, 162-189, No DOI.

\section{Keywords}

stress corrosion cracking; residual stress; AC current density; crystallographic texture; intergranular and transgranular cracks

\footnotetext{
(C) 2019 by the author(s). Distribute under a Creative Commans CC BY license
} 